\title{
Anaemia secondary to Escherichia coli mycotic aneurysm
}

\author{
Zhi Wan Wong (i), ${ }^{1}$ Kevin Ong (i) ${ }^{2}$
}

${ }^{1}$ Royal Perth Hospital, Perth, Western Australia, Australia ${ }^{2}$ Department of General Medicine, Armadale Health Service, Mount Nasura, Western Australia, Australia

Correspondence to Dr Zhi Wan Wong; melody.zhiwan@gmail.com

Accepted 7 December 2020

Check for updates

(C) BMJ Publishing Group Limited 2021. No commercial re-use. See rights and permissions. Published by BMJ.

To cite: Wong ZW Ong K. BMJ Case Rep

2021:14:e237997.

doi:10.1136/bcr-2020

237997

\section{SUMMARY}

Mycotic aneurysms can pose a diagnostic dilemma due to their variable presentations. We present a case of a 93-year-old man initially presenting with fevers, intermittent chest pain and normocytic anaemia refractory to repeated blood transfusions. He received intravenous ceftriaxone as Escherichia coli grew in his blood cultures. His chest X-ray showed a widened mediastinum. A subsequent $\mathrm{CT}$ of the chest discovered a mycotic aneurysm at the descending thoracic aorta. He had a good outcome and was thriving after 1 year post endovascular repair.

\section{BACKGROUND}

A mycotic aneurysm occurs when a new aneurysm is formed by infection of a native artery or when an existing aneurysm becomes infected. ${ }^{1}$ This condition is associated with high mortality and morbidity with high incidence of rupture. ${ }^{2}$ It can cause a range of symptoms from being asymptomatic to chest pain, abdominal pain, dysphagia, dysphonia and severe bleeding and shock in a ruptured aneurysm. ${ }^{1}$ Mycotic aneurysms account for $2.6 \%$ of all aortic aneurysms with the least likelihood of occurring at the thoracic aorta. ${ }^{1}$ Arterial injury, arterial luminal defect such as atherosclerotic plaque or ulceration, ${ }^{2}$ preceding infection, ${ }^{3}$ compromised immunity, diabetes, alcohol dependence, malignancy and advanced age are predisposing factors of mycotic aneurysms. ${ }^{1}$

Mycotic aneurysms should be suspected in elderly patients with arterial atherosclerosis, particularly in cases where the source of infection is unclear. ${ }^{14}$ Escherichia coli bacteraemia is frequently encountered in adult inpatient settings and is usually related to urinary tract infections or biliary sepsis. ${ }^{4}$ Mycotic aneurysms due to E. coli can occur rarely. ${ }^{1}$

We report a case of E. coli mycotic aneurysm associated with E. coli urosepsis in an elderly man with a background of chronic lymphocytic leukaemia. This case demonstrates the difficulty in making a diagnosis due to the wide differentials and range of symptoms and that prompt diagnosis that enables prompt medical and surgical interventions is life saving.

\section{CASE PRESENTATION}

This case involves a 93-year-old man who is living at home fairly independently. He presented with intermittent chest pain and dry cough starting fourdays prior associated with subjective fevers and vomiting. He had no lower urinary tract symptoms. On arrival, he was noted to be febrile at $39.7^{\circ} \mathrm{C}$. Other vital signs were normal. This is on a background of a low-grade chronic lymphocytic leukaemia treated with ibrutinib.

$\mathrm{He}$ had normocytic anaemia (haemoglobin: $77 \mathrm{~g} / \mathrm{L})$ and mildly raised total white cell count $\left(9.40 \times 10^{9} / \mathrm{L}\right)$ with predominant neutrophilia $\left(8.46 \times 10^{9} / \mathrm{L}\right)$. His $\mathrm{C}$ reactive protein $(\mathrm{CRP})$ was $170 \mathrm{mg} / \mathrm{L}$. Serial troponin levels were normal. His chest X-ray (CXR) done on admission showed a widened mediastinum, which was slightly dissimilar to his previous CXR on close inspection (figure 1). His admission ECGs showed sinus rhythm with left axis deviation but no ischaemic ST changes.

There was no clinical evidence of active bleeding, but his haemoglobin count dropped marginally to $72 \mathrm{~g} / \mathrm{L}$ one day after presentation. He received three units of packed red blood cells and his haemoglobin improved to $93 \mathrm{~g} / \mathrm{L}$. This started to downtrend the next day to $76 \mathrm{~g} / \mathrm{L}$ and he received another unit of packed red blood cells.

This patient was initially treated empirically for a community-acquired pneumonia with one dose of intravenous benzylpenicillin $1.2 \mathrm{~g}$ and oral doxycycline $100 \mathrm{mg}$. He was then commenced on regular intravenous ceftriaxone $1 \mathrm{~g}$ daily. Due to persistent fevers and growth of gram-negative bacilli in the patient's blood cultures, the ceftriaxone dose was increased to $2 \mathrm{~g}$ daily the next day. Antimicrobial cover was broadened on the third day by switching to intravenous piperacillin/tazobactam 4/0.5 g while awaiting sensitivities. A CT of the chest (figure 2) was performed on the fourth day of admission.

\section{INVESTIGATIONS}

On arrival to hospital, the patient's septic work-up included bloods, urine, nasal pharyngeal viral swabs and a CXR (figure 1). His bedside random bladder scan showed $135 \mathrm{~mL}$.

His blood film was reactive and the red cells showed moderate rouleaux. Otherwise, his haematinics screen, haemolysis screen and coagulation profile were unremarkable.

Although there was no prior history of urinary tract infection, due to gram-negative bacilli grown in the blood and urine cultures, a urinary tract CT was performed on the second day. It did not demonstrate hydronephrosis, significant renal calculi or a distended bladder.

A CT of the chest (figure 2) was performed due to ongoing chest pains, fevers, new pleural rub on auscultation and subtle evolving mediastinal changes on repeat CXR. It demonstrated an acute aortic syndrome with a large penetrating ulcer arising from the proximal descending thoracic aorta 


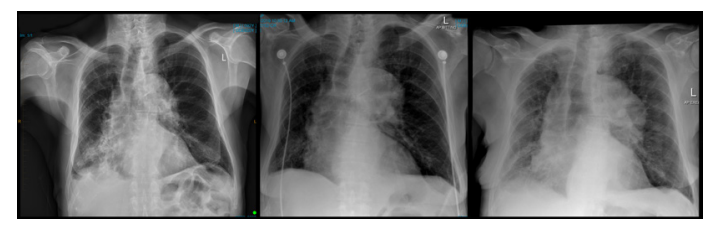

Figure 1 Chest X-ray (CXR) done 6 months prior to admission (left). Patient presented with non-productive cough at the time. Early consolidation in the right middle lobe was seen. CXR done on admission (middle). There was prominence of the aortic arch, coarsening of the bronchopulmonary markings bilaterally consistent with bronchiectasis and a small right pleural effusion. Follow-up CXR done on the third day of admission was not convincing of a new consolidation, but there was subtle expansion in the aortic arch (right).

with retrograde and antegrade extension of intramural haematoma along the distal aortic arch and the descending thoracic aorta.

\section{DIFFERENTIAL DIAGNOSIS}

The first CXR finding of a widened mediastinum was noted on presentation to hospital. However, the initial working diagnoses of community-acquired pneumonia contributing to pleuritic chest pain and anaemia secondary to chronic lymphocytic leukaemia were considered to adequately account for his presenting signs and symptoms.

He was subsequently thought to have concurrent urosepsis when gram-negative bacilli were grown in both his urine and all four initial blood culture bottles. They were then shown to be $E$. coli sensitive to amoxicillin and ceftriaxone.

Unfortunately, his chest pains recurred and his haemoglobin dropped significantly despite receiving blood transfusions the day before. Hence, upper gastrointestinal bleeding was considered. The underlying aetiology was initially under appreciated due to vague complains in the setting of worsening confusion from his delirium.

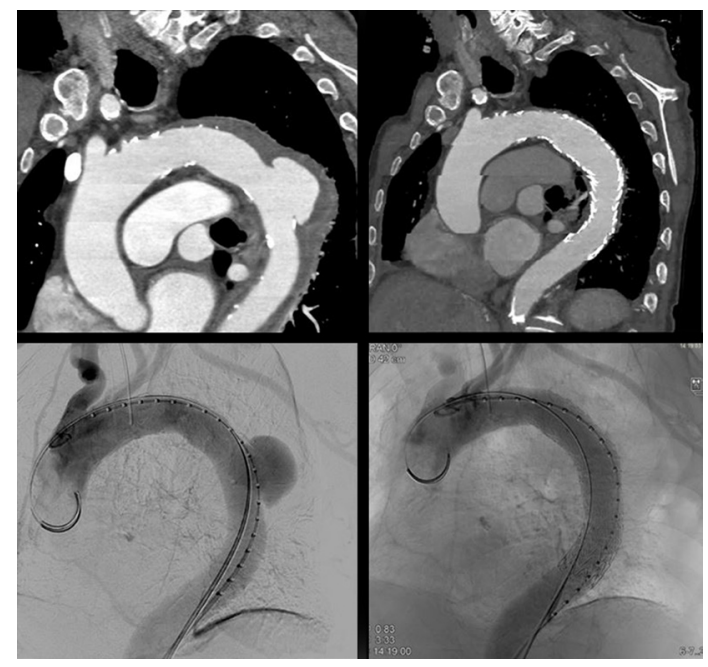

Figure 2 CT of the chest done on day 4 of admission showed a large outpouching seen arising from the posterior aspect of the descending aorta measuring $36 \times 22 \mathrm{~mm}$ with intramural haematoma (top left). CT angiogram of the thoracic aorta showing satisfactory appearance after thoracic endovascular aneurysm repair (TEVAR) with resolution of the aortic aneurysm (top right). Direct intensification image before TEVAR (bottom left) and immediately after TEVAR (bottom right).
After the CT of the chest was performed, it was realised that a mycotic aneurysm was the unifying diagnosis.

\section{TREATMENT}

The patient underwent a successful thoracic endovascular aneurysm repair on the fifth day of admission at a tertiary hospital (figure 2). He received intravenous ceftriaxone $2 \mathrm{~g}$ daily for 6 weeks in total. This was administered via a peripherally inserted central catheter when he was discharged. Immediately after completing the intravenous ceftriaxone course, the patient was commenced on lifelong oral amoxicillin given his graft insertion whilst actively infected.

\section{OUTCOME AND FOLLOW-UP}

The patient was discharged home 15 days after his operation. His repeat CT angiogram showed improvement in the aortic contour diameter (figure 2). Follow-up reviews in the vascular clinic and in the infectious diseases' clinic were very satisfactory. His CRP downtrended steadily to $17 \mathrm{mg} / \mathrm{L}$ after 9 months of treatment and eventually normalised at 17 months.

\section{DISCUSSION}

The majority of mycotic aneurysms are caused by gram-positive bacteria such as Staphylococcus species, Enterococcus species and Streptococcus pneumoniae. Other common pathogens include non-typhoidal Salmonella species. E. coli is considered a

\section{Patient's perspective}

I am lucky to be alive ... I feel great (1 year after surgery) and I feel like I did not even have surgery.

\section{Patient's next of kin's perspective}

I remember being called in by you and chatting to me and dad about what was happening and what was going to happen, the surgery. All I could think of at first was how are we going to get there (the tertiary hospital) and what I needed to do next. I do not think dad really understood what was going on. It took a bit of explaining and time before dad decided to go ahead with surgery.

Things were going well after the surgery. I was mainly worried about complications but felt better after speaking with the surgeon. After surgery, dad became aggressive and was not talking sense while he was in intensive care.

It was a few days before he was back to normal after the surgery. I am glad everything went well.

\section{Learning points}

- Escherichia coli bacteraemia in elderly patients with multiple comorbidities may not necessarily be solely due to urinary tract or intra-abdominal infections.

- Thoracic mycotic aneurysms should be considered in the setting of widened mediastinum on chest X-ray (CXR), respiratory symptoms like pleuritic chest pain and dry cough, persistent fevers and positive blood cultures.

- In such settings, prompt CT imaging to better characterise a prominent aortic arch when seen on CXR is highly recommended.

- Prompt diagnosis of mycotic aneurysm that enables prompt medical and surgical interventions is life saving. 
rare cause of this condition alongside with Haemophilus species, anaerobes and mycobacteria. ${ }^{15}$

Four cases of E. coli mycotic aneurysms have been reported. Two cases reported non-aortic mycotic aneurysms in the subclavian and internal carotid arteries. ${ }^{4}$ Multiresistant E. coli was cultured in three cases. Diagnoses were delayed in three cases and only two cases survived. The reported case without diagnostic delay involved an inpatient awaiting type 3 a dissecting aneurysm repair. This patient experienced low-grade fevers for 2 weeks, which escalated while awaiting surgery. An extended spectrum beta-lactamase producing E. coli was grown in the blood culture and there was an acute expansion of the aneurysm on repeat CT. ${ }^{6}$ All three reported cases which had delayed diagnoses involved persistent fevers despite at least 2 weeks of antibiotics treatment. ${ }^{14}$

An infected aneurysm occurs when the intima layer becomes diseased and bacteria then passes through into the deeper layers of the arterial wall. The bacteria proliferate and suppurate causing localised perforation and at times, a pseudoaneurysm forms as the wall degenerates. Atherosclerosis has been linked with the formation of mycotic aneurysm and hence, the aorta is commonly affected. However, mycotic aneurysms can also occur despite the absence of significant atherosclerosis. ${ }^{3}$

In this case, it is not determined if our patient had a preexisting aneurysm which became infected or if his aneurysm was caused by the E. coli infection. There is a possibility that he may have had an aneurysm prior given the findings of a widened mediastinum on his CXR from 6 months before admission and had not been previously investigated. However, the management of his condition would have remained unchanged either way.

The recommended initial medical treatment in Australia before blood culture and sensitivity results are available is intravenous vancomycin and ceftriaxone $2 \mathrm{~g}$ daily. ${ }^{5}$ With medical treatment alone, the survival rate is roughly $10 \%$. A combination of prompt medical therapy and vascular surgery can lead to survival rates of about $62 \% .^{1}$ Other studies report mortality rates of infected abdominal aortic aneurysms to be between $23 \%$ and $31 \% .^{2}$ Hence, managing mycotic aneurysms require a multidisciplinary approach, including the infectious diseases team, the vascular team and radiology.

Contributors ZWW formulated the idea for the case report, performed literature search and wrote the manuscript. KO provided comments to the initial draft and assisted with copyediting. All authors contributed to, made revisions and approved the final manuscript.

Funding The authors have not declared a specific grant for this research from any funding agency in the public, commercial or not-for-profit sectors.

Competing interests None declared.

Patient consent for publication Obtained.

Provenance and peer review Not commissioned; externally peer reviewed.

\section{ORCID iDs}

Zhi Wan Wong http://orcid.org/0000-0001-6973-748X

Kevin Ong http://orcid.org/0000-0001-6204-0989

\section{REFERENCES}

1 Rajendran R, Malik H, Richardson T. Escherichia coli and mycotic thoracic aortic aneurysm: a case report. Grand Rounds 2012;12:27-31<http://www.grandrounds-emed.com>

2 Kim Y-W. Infected aneurysm: current management. Ann Vasc Dis 2010;3:7-15.

3 Denis S. UpToDate: Overview of infected mycotic arterial aneurysm [Internet]. Uptodate. com, 2020. Available: https://www.uptodate.com/contents/overview-of-infectedmycotic-arterial-aneurysm [Accessed 10 May 2020].

4 McCann JF, Fareed A, Reddy S, et al. Multi-resistant Escherichia coli and mycotic aneurysm: two case reports. J Med Case Rep 2009;3:6453 http://jmedicalcasereports. com/jmedicalcasereports/article/view/3/3/6453

5 Infected Aneurysms. Therapeutic guidelines LTD (eTG March 2020 edition), 2019. Available: http://www.tg.org.au [Accessed 27 Apr 2020].

6 pp.Takahashi Y, Tsutsumi Y, Monta O, et al. Mycotic aneurysm of the thoracic aorta caused by extended-spectrum beta-lactamase-producing Escherichia coli. Interact Cardiovasc Thorac Surg 2011;12:61-2 https://academic.oup.com/icvts/article-abstract/ $12 / 1 / 61 / 654923$

Copyright 2021 BMJ Publishing Group. All rights reserved. For permission to reuse any of this content visit

https://www.bmj.com/company/products-services/rights-and-licensing/permissions/

BMJ Case Report Fellows may re-use this article for personal use and teaching without any further permission.

Become a Fellow of BMJ Case Reports today and you can:

- Submit as many cases as you like

- Enjoy fast sympathetic peer review and rapid publication of accepted articles

- Access all the published articles

Re-use any of the published material for personal use and teaching without further permission

Customer Service

If you have any further queries about your subscription, please contact our customer services team on +44 (0) 2071111105 or via email at support@bmj.com.

Visit casereports.bmj.com for more articles like this and to become a Fellow 